\title{
DOES THE PROPOLIS REINFORCE THE AUTOCLAVED BONE ALLOGRAFT AND DOES IT HAVE AN IMMUNOMODULATION EFFECT?
}

\author{
Abdellatif Boudra ${ }^{1}$ \\ ${ }^{\prime} I b n$ Khaldoun University, Veterinary Institute of Tiaret, Surgery Service, Agro-Industrial Department Manager of Mahassil \\ Company NH group, Algeria
}

\begin{abstract}
The loss of bone substance in diaphyseal region of long bones is a common problem faced by veterinarian orthopedic surgeon. In order to recover from cortical bone defect our study proposes to implant an autoclaved orthotopic allograft of one centimeter length and compares effects of covered and uncovered bones with propolis in the femoral diaphysis under general anesthesia and sterile condition. The experiment involved eight adult dogs, from local breed and different sex; split into two groups. An autoclaved allograft without propolis was implanted for the first animals group (control group) then the same graft has been implanted to the second animals group. The aim of our study is to determine whether the propolis resin can diminish the fragility of autoclaved allografts that was confirmed by the resistance of the graft covered with propolis even once the osteosynthesis material is removed and if the autoclaved grafts covered by the propolis used in our experiments have not suffered resorption despite the intensity of the immune response during the first month.The results show that all grafts covered with propolis remained unbroken and have not suffered of the resorption problems.
\end{abstract}

Keywords: Propolis, Autoclaved allograft, Radiography graft resorption bursting graft.

\section{Contribution/ Originality}

This study is one of very few studies which has investigated both phenomena resorption and fragility of the autoclaved allograft. Extract propolis purchased was used in vivo and its advantages were highlighted

\section{INTRODUCTION}

Propolis has attracted much attention in recent years as a useful or potential substance used in medicine and cosmeticsproducts $[1]$.

Health industry has always used the natural product as an alternative [2], Currently, the propolis is studied due to its ability to improve the regeneration of bone loss [3] .The allograft is an alternative to the massive segmental bone loss but has several drawbacks, this includes failure of incorporation, risk of infection, and the alteration of mechanical properties with time resulting in the fracture of the graft [4]. The introduction of propolis in our study has opened new 
perspectives for the use of this substance in orthopedic surgery [5].In our study we want to if the propolis resin can diminish the fragility of autoclaved allografts even once the osteosynthesis material is removed and if the autoclaved grafts covered by the propolis used in our experiments have not suffered resorption despite the intensity of the immune response during the first month.

\section{MATERIALS AND METHODS}

\subsection{Experimental Animals}

We have chosen to conduct our experiment on eight (08) local breed dogs (different sexes) aged between 6 and 12 months with an average body weight of around $15 \mathrm{~kg}$. All animals were dewormed by using Flubendazole at $75 \mathrm{mg} / \mathrm{kg}$ (FLUVERMAL ${ }^{\circledR}$; Janssen-Cilag; France; 100mg/comprimé) and a control collar was secured around dog's neck to prevent infestation of external parasites. Thereafter, the animals were left in separate cages for an adaptation period of 15 days.

\subsection{Graft Preparation}

The graft is obtained from the diaphysis of the left femur of an euthanized dog, after removal of the periosteum, bone and muscle insertions of residues, the shaft is cut by using a stainless metal saw into fragments of $1 \mathrm{~cm}$ length. The grafts in the control group are put directly in special sealed bags (SteriCleanISO 11607 REF 230112 LOT 3006715062011 20cm /200 m). Other grafts are similarly prepared, except an additional step where in the sold propolis extract (ArkogéluleArkopharma 45 capsules 22.3gr, 250mg/capsule France $\mathrm{N}^{\circ}$ de lot BCP00865B) is applied to the integrity of the graft before it is placed in bags for sterilization. The grafts are prepared then autoclaved at a temperature of $121{ }^{\circ} \mathrm{C}$ (Webeco $\mathrm{GmbH}$ type A N ${ }^{\circ} 919995$ made in Germany Watt 2700 Amp 12).

\subsection{Anesthetic Protocol}

Anesthetic premedication protocol has been started with $0.01 \mathrm{mg} / \mathrm{Kg}$ atropine injected subcutaneously (Atropine ${ }^{\circledR}$ sulfate (0,1\%) : Lab RENAUDIN ; N 112992 ; France), followed after 15 minutes by a double injection intramuscularly of acepromazine (CALMIVET ${ }^{\circledR}(0.5 \%)$ : Vetoquinol ; France) and buprenorphine (Temgesic ${ }^{\circledR}(0,3 \mathrm{mg} / \mathrm{ml})$ :Schering-plough; LevalloisPerret; France) at $0.2 \mathrm{mg} / \mathrm{kg}$ and $0,02 \mathrm{mg} / \mathrm{Kg}$ respectively. Propofol at an $8 \mathrm{mg} / \mathrm{Kg}$ was injected slowly by intravenous injection to ensure the induction operation. Just before starting the operation, half mixture of tiletamine and zolazepam at a rate of $15 \mathrm{mg} / \mathrm{kg}$ was injected to maintain anesthesia during surgery, the second half was injected 45 minutes after and if necessary small amounts may have been added throughout the operation . 


\subsection{Surgical Technique}

The spindle is inserted through the proximal end with a mandrel Jacobson, it engages in a retrograde manner into the medullary canal of the proximal portion held by a clamp to bone, the diameter of the pin must represent $50-70 \%$ of the medullary cavity. The pin is slid along the medullary canal up to the trochanteric fossa, a skin incision is made at the raised portion by the spindle. Three quarters of the pin remain outside this opening .Once the proximal and distal portion of the bone are drilled using a Steinmann pin $2 \mathrm{~mm}$ diameter, in order to get the stainless wire of $0.6 \mathrm{~mm}$ in diameter to produce a hemi strapping. The complete insertion of the pin is estimated by a spin of the same length loaded in parallel with the lodged pin, thereafter, the remainder is cut with a cutting pin. the powder of antibiotic has been applied at both wounds. Finally the fascia suture has been done in overlock by a synthetic absorbable suture "polyglactin $\mathrm{O} / 2$ ". The closure of the skin is ensured by simple points separated polyamide $0 / 2$ and the wound is cleaned with betadine.

After injection of an analgesic, the animal is monitored until awakened, then placed in an individual cage in order to limit the movements.

\subsection{Radiological Monitoring}

A Digital radiography machine was used to follow up the quality of the callus, and the fate of the graft until extraction pin. Radiographs are taken on a bi-monthly basis in side view, to properly highlight the femur.

Table-1. Complications recorded during the clinical follow - up

\begin{tabular}{|c|c|c|}
\hline Animals and graft types & & Graft reaction \\
\hline \multirow{4}{*}{ Graft without propolis } & $\mathrm{N}^{\circ} 1$ & Graft bursting at 15 days \\
\hline & $\mathrm{N}^{\circ} 2$ & Graft bursting at 15 days \\
\hline & $\mathrm{N}^{\circ} 3$ & Resorption of the graft at 45 days \\
\hline & $\mathrm{N}^{\circ} 4$ & Unbroken graft \\
\hline \multirow{4}{*}{$\begin{array}{ll}\text { Graft } & \text { cove } \\
\text { propolis }\end{array}$} & $\mathrm{N}^{\circ} 1$ & Unbroken graft \\
\hline & $\mathrm{N}^{\circ} 2$ & Unbroken graft \\
\hline & $\mathrm{N}^{\circ} 3$ & Unbroken graft \\
\hline & $\mathrm{N}^{\circ} 4$ & Unbroken graft \\
\hline
\end{tabular}

The postoperative complications recorded, are mainly in relation with the use of graft non covered with propolis, among these complications we include brek (either due to bursting graft or resorptionone) Table $\mathrm{N}^{\circ}$. 
International Journal of Advances in Life Science and Technology, 2014, 1(2): 54-59

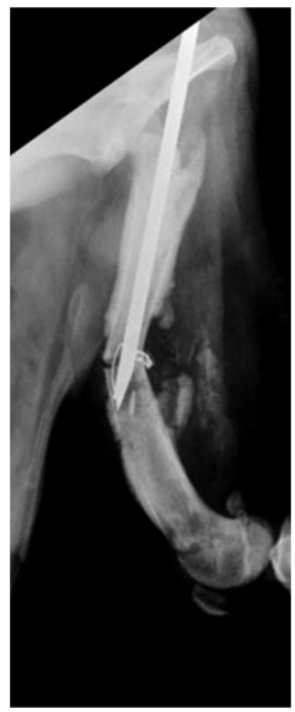

Figure-3.Radiography at 15 days, shows the breakdown of graft uncovered propolis, the output pin, very visible angulation.

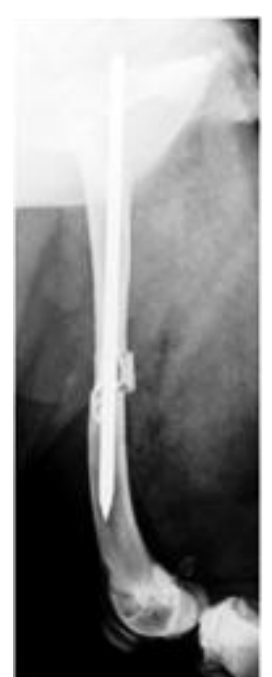

Figure-4. Postoperative radiography (case $\mathrm{N} 3$ graft uncovered propolis) shows the implementation of a graft

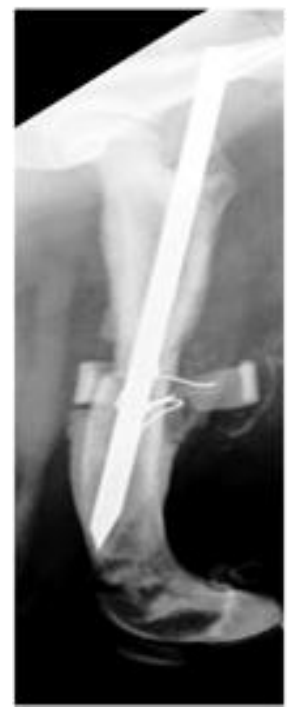

Figure-2.Radiography at 15 days, shows the breakdown of graft uncovered propolis.

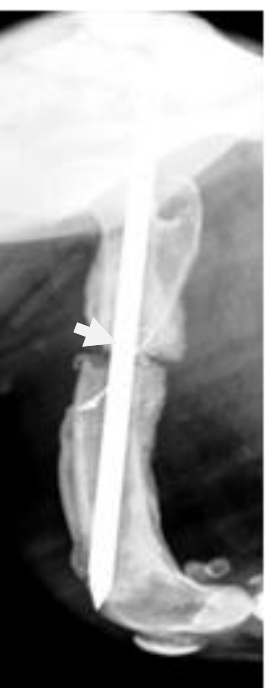

Figure-5.Radiography at 45 days (N 3 graft cases uncovered propolis), the white arrow indicates a complete resorption of the graft, where the appearance of a discontinuity which results in a radiotransparent

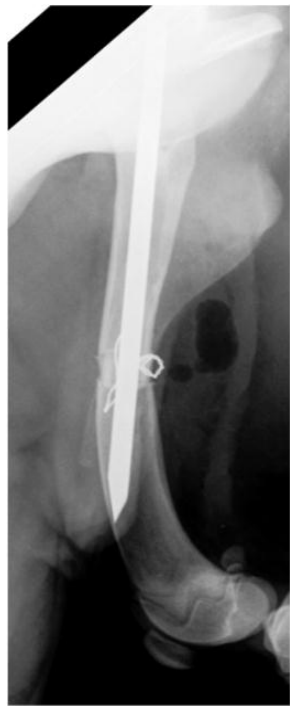

Figure-1. postoperative radiograph shows a graft without propolis implemented the same diameter as the recipient bone immobilized by intramedullary nailing and reinforced by a single wire inoxydable

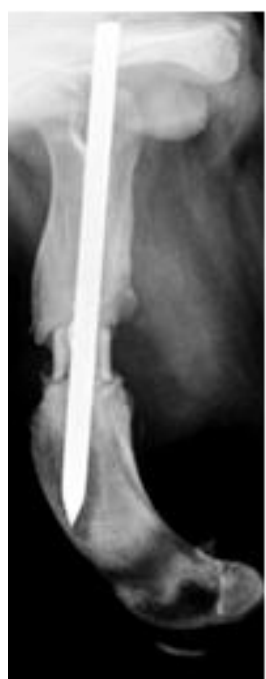

Figure-6. Radiography at 60 days (case N 3 graft covered with propolis) graft still in place and has not been modified.

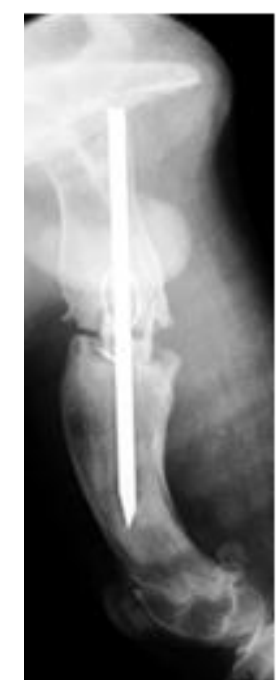

Figure7.Radiography at 75 days (case $\mathrm{N} 4$ graft covered with propolis) shows a graft still in place and has not been modified. 


\section{DISCUSSION}

The beneficial effects of propolis appear to be worthy of their therapeutic efficiency [4]. The results of the clinical follow-up showed a recovery of all dogs treated with propolis graft covered with a minimum of post-operative complications.The bursting of the graft is the main complication encountered during bone graft [6]. The autoclaving method xenografts reduced the risk of infection but sterilization causes the decrease of graft resistance to compression, up to $70 \%$ [7]. The results show that all grafts covered with propolis remained unbroken, while $50 \%$ of grafts uncovered with propolis broke up figure $\mathrm{N} 2$ and 3, we register two advantages thanks to the use of propolis, first it improves the brittleness caused by autoclaving, second it prevents from disease transmission. The shaft has healed after approximation of the two end pieces and the output pin at the distal metaphysis favored by the anatomical appearance (curvature) of the femur figure $\mathrm{N}$ 5; the allograft inflammatory reaction develops with the presence of many cells for several weeks ( two months) after this period, a fibrous casing isolates the graft and limiting the immunological problems, These reactions will be more important that the graft will be fresh and unprocessed [8] Autoclaved grafts covered by the propolis used in our experiments have not suffered resorption despite the intensity of the immune response during the first month, this is due to the immunomodulation effects of propolis[9]. and due to the flavonoids present in the coffeic acid propolis that play an important role in the decrease of the immune response, by inhibiting the lipoxygenase pathway of arachidonic acid [10].

\section{CONCLUSION}

The autoclave sterilization allows transplants and prevent the transmission of diseases but instead, it leads to a weakening of the graft, this defect has been corrected and even improved due to the use of propolis coat covering the allograft, which was confirmed by the resistance of the graft covered with propolis once the osteosynthesis materials are removed .

Our study confirmed that propolis has an immunomodulatory effect, protecting against the risk of graft rejections and failure.

\section{REFERENCE}

[1] L. Mahmoud, "Biological activity of bee propolis in health and disease," Asian Pac. J. Cancer. Prev., vol. 7, pp. 22-31, 2006.

[2] A. Parolia, S. Thomas, M. Kundabala, and M. Mohan, "Propolis and its potential uses in oral health," I. J. Med. Medical. Sciences, vol. 2, pp. 210-215, 2010.

[3] A. L. Andrade, D. Manzi, and R. Z. Domingues, "Tetracycline and propolis incorporation and release by bioactive glassy compounds, science directe," J Non-Crystalline Solids, vol. 352, pp. 3502$3057,2006$.

[4] J. M. Grange and R. W. Davey, "Antibacterial properties of the propolis (Bee Glue)," J Royal. Society. Med., vol. 83, p. 159, 1990.

[5] A. Boudra, M. Hamdi, and K. Amara, "Role of propolis in osteointegration in allograft autoclaved implanted in femur of dog," J Veterinar Sci Technolo., vol. 5, p. 2, 2014. 
[6] F. F. Parrish, "Allograft remplacement of all or part of the end of a long bone following excision of tumor, report of twenty-one cases," J. Bone joint. Surg., vol. 55, pp. 1-22, 1973.

[7] L. E. Miller and J. E. Block, "Prospective on the clinical utility of allograft for bone regeneration with osseous defects," Orthopedic Research and Reviews, vol. 3, pp. 31-37, 2011.

[8] D. Mathon, "Grafts and bone substitutes, CES musculoskeletal trauma and animal orthopedics," pp. 18-22, 2002.

[9] T. Farooqui and A. A. Farooqui, "Beneficial effects of propolis on human health and neurological diseases," Frontiers in Bioscience, vol. 4, pp. 779-793, 2012.

[10] PAROLIA, "Propolis and its potential uses in oral health," International Journal of Medicine and Medical Sciences, vol. 2, pp. 210-215, 2012. 